\title{
No Waste by Default: Nudging to Prevent Food Waste in
}

\section{Restaurants}

\author{
Cesareo $\mathbf{M}^{3 *}$, Oppo $\mathbf{A}^{2,3}$, Lopes $\mathbf{M E}^{3}$, Vaccaro $\mathbf{M}^{3}$, Stoyanova $\mathrm{PS}^{3}$, \\ Pozzi F1,3 and Moderato $\mathrm{P}^{1,3}$ \\ ${ }^{1}$ IULM, International University of Languages and Media, Italy \\ 2Sigmund Freud University, Italy \\ ${ }^{3}$ IESCUM, Istituto Europeo per lo Studio del Comportamento Umano, Italy
}

\section{Research Article \\ Volume 3 Issue 1}

Received Date: December 04, 2018

Published Date: January 09, 2019

DOI: $10.23880 /$ eoij-16000191

*Corresponding author: Massimo Cesareo, IESCUM, Istituto Europeo per lo Studio del Comportamento Umano, P.le Ravenet n.5 43100 - Parma, Italy, Tel: (+39) 3297320548; Email: massimo.cesareo01@gmail.com

\begin{abstract}
Nudge techniques concern any aspect of the choice architecture that alters people's behavior in a predictable way without forbidding any options or significantly changing their economic incentives. In order to tackle the problem of food waste in restaurants, a nudge intervention was developed to increase the demand of "doggy bag" in a restaurant close to Milan. In the intervention the default rule was manipulated to automatically provide with a doggy bag the customers who had uneaten food in their plates, unless they actively choose to opt out. Data showed that, in the experimental condition, the number of doggy bags demanded was more than doubled compared with the control one suggesting the effectiveness of the intervention.
\end{abstract}

Keywords: Food Waste; Nudge; Default Rule; Leftovers; Doggy Bag

\section{Introduction}

As stated by Sunstein and Thaler, a nudge is "any aspect of the choice architecture that alters people's behavior in a predictable way without forbidding any options or significantly changing their economic incentives" [1]. From a behavioral standpoint this definition stresses some main points. A nudge is any deliberate attempt to (1) work on the context, (2) in order to alter the probability of emission of a behavior, (3) and influence it in a predictable way, (4) without punishing alternative behavioral responses, suppressing alternative choices or providing significant economic rewards.
Although not explicitly stated, the majority of the techniques used in nudging interventions are mainly modifications of antecedents, in order to set the occasion for emitting the desired behavior [2]. The literature shows the effectiveness of nudging in many different domains from social policies to sustainability, using a broad range of techniques in order to promote prosocial behaviors [3-5]. Among these the manipulation of the default rule turned out to be effective in different case studies which promoted desirable behaviors according to the idea of libertarian paternalism [6-8]. An example of how default rule works is a case study carried out by 


\section{Ergonomics International Journal}

Johnson and Goldstein [6]. The authors found out that the percentage of organ donors in the EU countries was distributed following two patterns. The countries where people had to actively choose to become organ donors showed a very low percentage of donors. Conversely, the countries in which people were considered to be organ donors by default, unless they actively choose to opt-out, the percentage was much higher, and in many countries close to $100 \%$.

Although, in the last decade the literature has been concerned to change socially relevant behaviors through "nudge techniques", there are fields that remain unexplored, and one of them is the food waste issue. In recent years the debate about food waste has been a hot issue within the international community, since about one third of the produced food is wasted every year worldwide [9-12]. Today around 34\% of food consumption takes place out of home and one third of it in public places like restaurants [13-15]. Unfortunately, not all of the food ordered by the customers in the restaurants is being consumed, so leftovers are often thrown away. Reducing the amount of leftovers thrown away could have a significant economic and environmental impact on a large scale $[10,16,17]$.

In Italy, a law (n. 166/16) to tackle food waste was recently approved. Specifically, Article 9 specifically refers to the reduction of waste in restaurants and to the increase of the availability of "doggy bags". In Italy, according to a survey made by Coldiretti [13], around $21 \%$ of food waste comes from restaurants and one of the sources of waste is leftovers [18]. Usually, clients have to actively ask the waiters to pack their leftovers into the socalled "doggy bags", and surveys show that only the 36\% of customers ask for their leftovers [19-21].

Following the "nudge principle" stated above, it has been hypothezised that the manipulation of the default rule to automatically provide people with a "doggy bags" would have increased their demand. In this pilot intervention the default rule was manipulated to automatically provide a doggy bag to all customers who had uneaten food in their plates, unless they actively choose to opt- out. This study, aimed to tackle food waste in restaurants through intervention based on reducing the response cost in requesting a "doggy bag" for the leftovers.

\section{Materials and Method Setting}

Data were collected at dinner time, from 7.00 P.M. to 12.00 A.M. in a small restaurant close to Milan, hosting around 55 to 60 people per meal. The restaurant was mostly serving pizza, chosen as the target food for our experiment. Considering that the measurements were self-reported, a context with a small number of customers was chosen in order to increase the reliability of the data collected during the intervention. Indeed, in a bigger restaurant a higher number of employees would have been involved in gathering data, therefore increasing the risk of mistakes.

\section{Materials}

In order to manipulate the default rule one doublesided poker chip was used, placed in front of each client of the restaurant. The chip was green on one side and red on the other one. To make the rationale of the intervention easily understandable for the customers table centrepieces were developed (Figure 1) with instructions about what to do with the poker-chip in order to obtain the doggy bag. Moreover, menu flyers with information about food waste and the same set of instructions were available on the centrepieces (Figure 2).

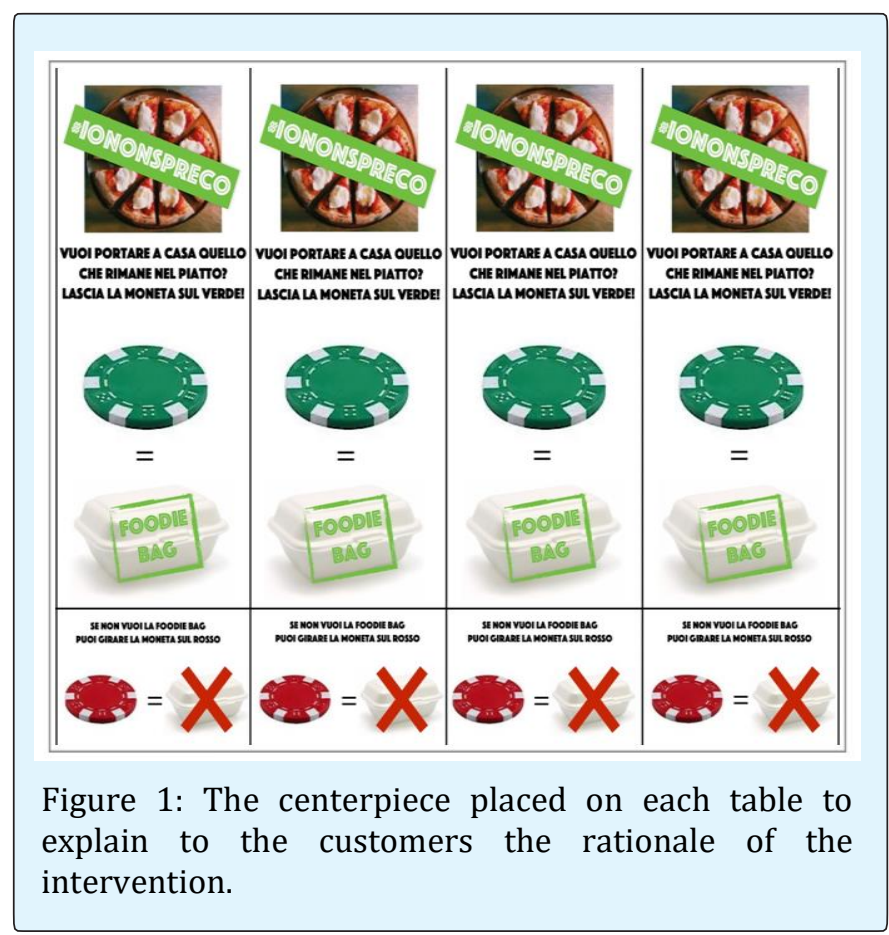




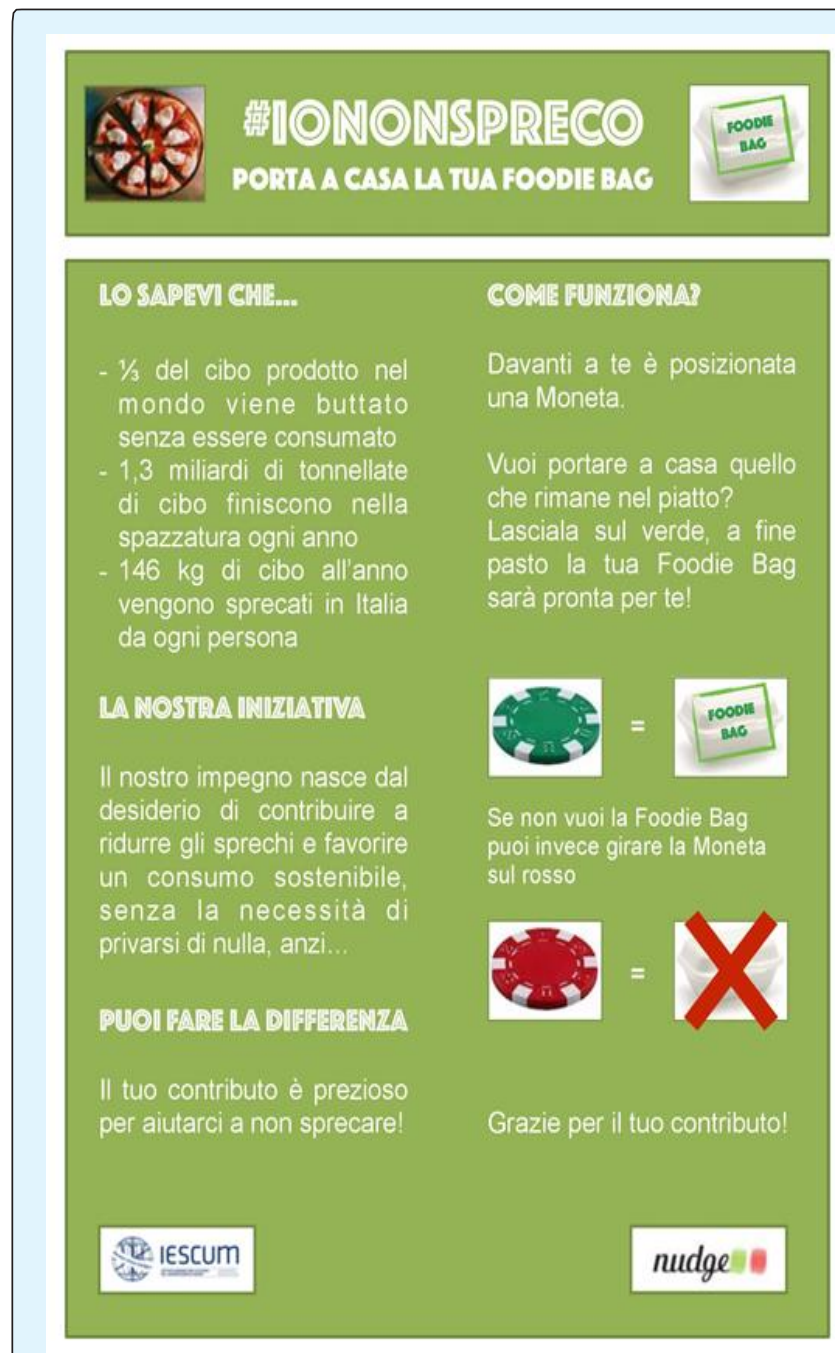

Figure 2: The flyer placed within each menu to explain to the customers the rationale of the intervention and providing them information about food waste.

\section{Measures}

The restaurant staff was provided with an observational grid placed in the kitchen on which they were trained to note an " $x$ " for any plate with leftovers (Figure 3). In order to collect data about the demand for doggy bags, stickers were provided to be put on each one of the doggy bag given to the customers. In this way, it was possible to easily count the number of doggy bags given out during each phase of the research. During the experiment any plate with inside at least one slice of pizza was considered as having leftovers.

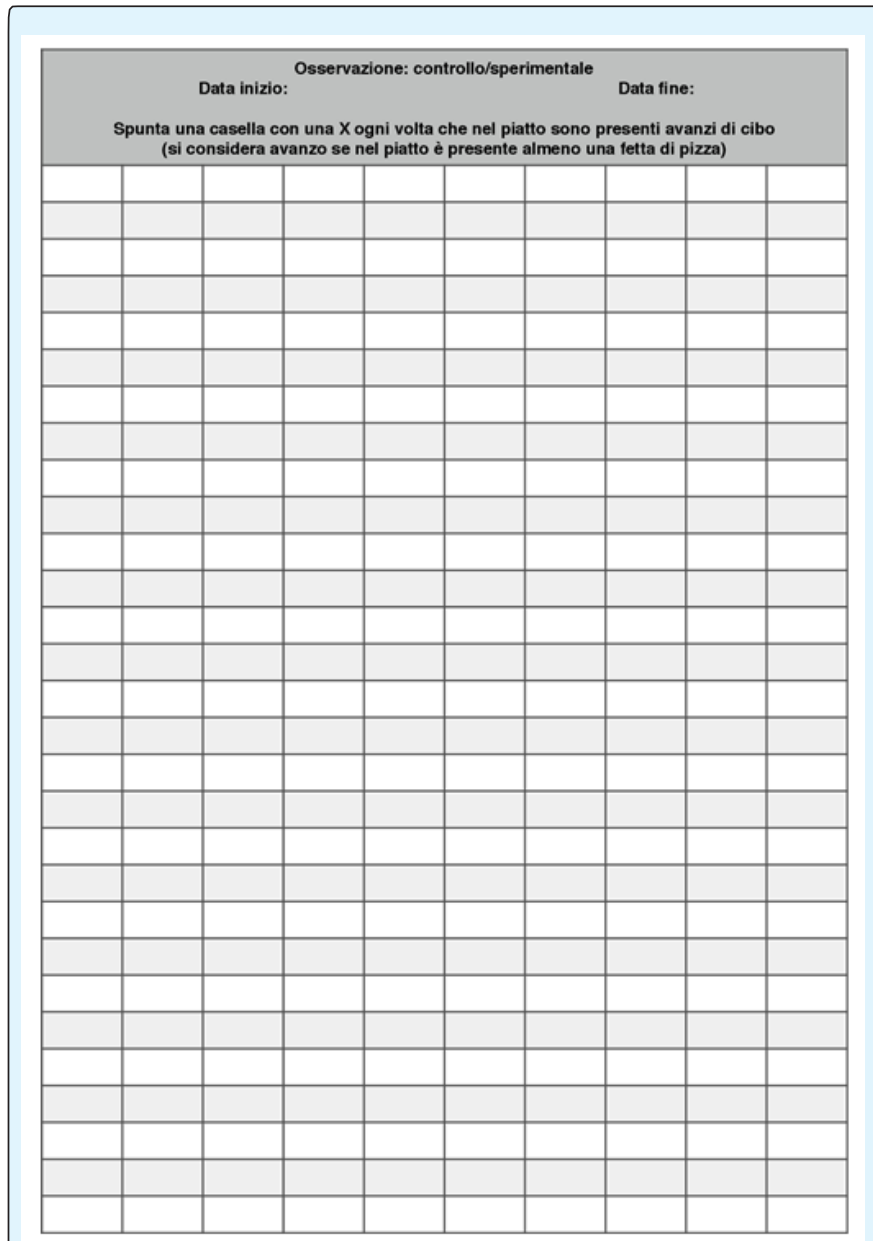

Figure 3: The observational grid used to gather data about the number of plates with leftovers.

\section{Procedures}

Data were collected for one month: two weeks for the control phase and two weeks for the experimental one. During the control phase it was simply measured the demand of doggy bags as described above. During the experimental phase, the double-sided poker chips were placed on the tables, with the green side up, in front of each client. To request a doggy bag, the clients just had to leave the chip on the green side (default rule), otherwise, they had to turn the red side up. A centrepiece was placed on each table, and the flyer with the instructions was placed inside each menu.

\section{Experimental design}

Between groups plan was implemented, with an independent variable (intervention vs. non- intervention) 


\section{Ergonomics International Journal}

and two independent groups, with repeated measures on the dependent variable. The dependent variable was the number of doggy bags requested by the customers.

\section{Results}

Overall, forty-six and forty leftovers were left in the control phase and in the intervention phase respectively. In the control phase nineteen customers (41\%) asked for the doggy bag, and in the intervention phase thirty-four customers (85\%) asked for the doggy bag. A chi-square test was used in order to compare the data in the two conditions. The demand of doggy bags was $44 \%$ higher during the experimental phase compared with the control one (Figure 4). The difference showed to be statistically significantly (chi-square $(1)=15.48 \mathrm{p}<.001$ ), and the effect size showed that in the experimental phase the likelihood of demanding a doggy bag was about eight-fold higher than in the control phase (OR $=8.05$; 95\% CI: 2.82 22.96).

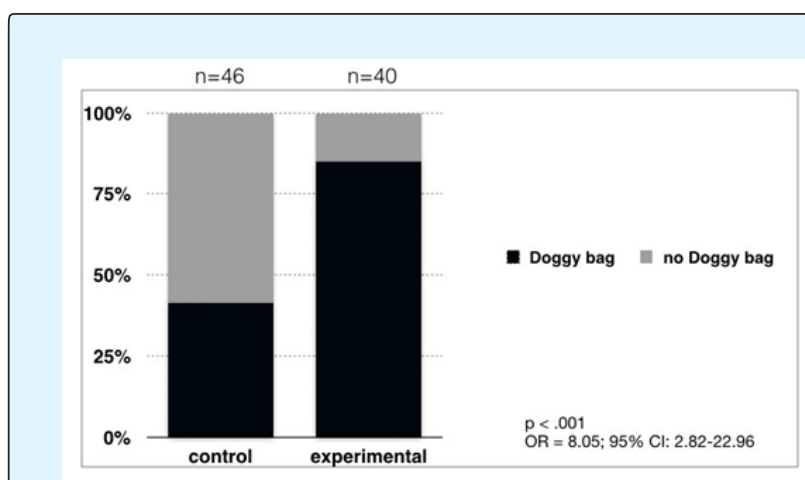

Figure 4: The histograms show the percentage of subjects who chose the doggy bag out of the overall number of people who had leftovers in their plates at the end of the dinner.

\section{Discussion}

The importance of the context to influence people's behavior is crucial when talking about nudging. The experiment tested the effectiveness of a nudging intervention for reducing food waste in a restaurant supporting the experimental hypothesis with a statistically significant difference between the control and the experimental phase. Indeed, in the experimental condition, the number of doggy bags demanded was more than doubled compared with the control one.
Moreover, by manipulating the default rule the probability that a customer with leftovers would ask for a doggy bag increased. In light of these results, we can say that nudge interventions can be effective and sustainable to deal with the problem of food waste in restaurants.

The results of the present paper should be interpreted keeping in mind that the study population was fairly small. In the current study, the nudge intervention could not discriminate between the informative part (information about food waste) and the default rule part (customers don't have to ask actively for the doggy bag).

To compare the effectiveness of the default rule vs. mere informative approach, another condition could be set for example providing clients with mere informational flyers and centrepieces without manipulating the default rule. To test the generalisation of the intervention would be interesting to apply the same experimental design in restaurants where it is served food which is different from pizza. Furthermore, many people go back to work after the lunch break and might not like to carrying food with them back to the office. Thus the chance that they require their leftovers could decrease. Therefore to replicating the same intervention at lunchtime would be of some interest.

Cultural specifics could also be a crucial variable in influencing people's choices about the demand of doggy bags in restaurants. However, as Johnson and Goldstein [6] showed in their work, default rules seem to affect people's behaviors regardless of their cultural background. For this reason testing the intervention in other countries with different cultures and traditions would be interesting.

Ethical Approval: All procedures performed in the study were in accordance with the ethical standards of the institutional and/or national research committee and with the 1964 Helsinki declaration and its later amendments or comparable ethical standards.

Acknowledgement: The Authors wish to acknowledge the help of Mattia Besana and the staff of Rise Live Bistrot in gathering the data.

\section{References}

1. Thaler RH, Sunstein CR (2008) Nudge: improving decisions about health, wealth and happiness. Yale University Press. 


\section{Ergonomics International Journal}

2. Sunstein CR (2014) Nudging: a very short guide. Journal of Consumer Policy 37(4): 583-588.

3. Bailenson JN, Hershfield HE, Goldstein DG, Sharpe WF, Fox J, et al. (2011) Increasing saving behavior through age-progressed renderings of the future self. Journal of Marketing Research 48: S23-S37.

4. Costa DL, Kahn ME (2013) Energy conservation "nudges" and environmentalist ideology: evidence from a randomized residential electricity field experiment. Journal of the European Economic Association 11(3): 680-702.

5. Kallbekken S, Sælen H, Hermansen EA (2013) Bridging the energy efficiency gap: A field experiment on lifetime energy costs and household appliances. Journal of Consumer Policy 36(1): 1-16.

6. Johnson EJ, Goldstein DG (2003) Do defaults save lives? Science 302(5649): 1338-1339.

7. Pichert D, Katsikopoulos KV (2008) Green defaults: Information presentation and pro-environmental behaviour. Journal of Environmental Psychology 28(1): 63-73.

8. Keller PA, Harlam B, Loewenstein G, Volpp KG (2011) Enhanced active choice: A new method to motivate behavior change. Journal of Consumer Psychology 21(4): 376-383.

9. FAO (2011) Global Food Losses and Food WasteExtent, Causes and Prevention. UN Food and Agriculture Organization, Rome.

10. FAO (2013) Food wastage footprint, Impacts on Natural resources: Summary report. UN Food and Agriculture Organization, Rome.

11. Monier V, Mudgal S, Escalon V, O'Connor C, Anderson G, et al. (2011) Preparatory study on food waste across EU 27. European Commission, Paris, France.
12. Gustavsson J, Cederberg C, Sonesson U, Van Otterdijk R, Meybeck A (2011) Global food losses and food waste. Food and Agriculture Organization of the United Nations, Rome.

13. Censis C (2010) Primo rapporto sulle abitudini alimentari degli italiani. Sintesi dei principali risultati. First report on Italian food habits: A summary of main results. Censis- Coldiretti, Rome, Italy.

14. Fontanelli R, Lonardi G (2011) McItalia. Il bel paese a tavola fuori casa. Rubbettino Editore.

15. Segrè A, Falasconi L (2011) Il libro nero dello spreco in Italia: il cibo. Edizioni Ambiente, pp: 1-128.

16. Commissione Europea (2014) Impact Assessment On Measures Addressing Food Waste To Complete Swd 207 Regarding The Review Of Eu Waste Management Targets. Bruxelles.

17. Thönissen R (2009) Food wastes: The Netherlands. Presentation to the EU Presidency Climate Smart Food Conf Lund.

18. Parfitt J, Barthel M, Macnaughton S (2010) Food waste within food supply chains: quantification and potential for change to 2050. Philosophical Transactions of the Royal Society of London B: Biological Sciences 365(1554): 3065-3081.

19. Paladino LM (2015) Lo spreco alimentare domestico: un'indagine quali-quantitativa.

20. Gaiani S (2013) Lo spreco alimentare domestico in Italia: stime, cause ed impatti. Alma Mater Studiorum Università di Bologna. Dottorato di ricerca in Economia e politica agraria ed alimentare.

21. Coldiretti (2016) Consumi: coldiretti/ixè, 1 italiano su 3 chiede avanzi al ristorante ma per il 22\% la doggy bag è volgare o si vergogna. News. 